\title{
Yes, we Fuck! El Grito de la Alianza Queer-Crip
}

\author{
Andrea García-Santesmases Fernández \\ Universidad de Barcelona - Miembro del proyecto Yes, we fuck! \\ andrea.gsantesmases@gmail.com
}

He practicado relaciones sexuales plenas, más de lo que la mayoría probablemente habría imaginado, y mисho, mucho menos de lo que me hubiera gustado en la vida. No lo comentaba casi nunca para evitar desaprobaciones inútiles e innecesarias. Pero en esta lista de cosas por las que mi vida ha merecido la pena el sexo no podía faltar.

Panegírico, Paco Guzmán, filósofo

$\mathrm{y}$ activista con diversidad funcional

\section{Documentando un Nuevo Imaginario}

¿Los 'discapacitados' follan? Y si así, ¿cómo lo hacen? ¿Y con quién? A muchas personas, en un momento $\mathrm{u}$ otro, nos han surgido estas dudas. No obstante, las hemos silenciado, avergonzadas por tener pensamientos tan indecorosos, máxime cuando se refieren a personas consideradas asexuales, 'ángeles, niños eternos'... Pero estas preguntas son importantes porque ponen en cuestión esa supuesta asexualidad y remiten a nuestra construcción cultural en torno a qué cuerpos consideramos (in)válidos para el placer. Partiendo de la necesidad de empezar a contestar colectiva y políticamente a dichas cuestiones, en el año 2012 comenzamos el proyecto Yes, we fuck! Se trata de un documental que muestra imágenes explícitas de cuerpos no normativos, de personas, parejas e interacciones que escapan a las concepciones habituales de belleza, deseo y práctica sexual. El objetivo es visibilizar que las personas con diversidad funcional $^{1}$ son seres sexuales: deseantes, claro, pero también deseables.

A raíz de la filmación del documental, se ha generado un proceso de sinergia entre diferentes activismos que ha venido (auto) denominándose alianzas queer-crip o alianzas tullido-transfeministas ${ }^{2}$. Dentro de ese queer se incluyen diferentes sensibilidades activistas (feministas, lesbianas, gordas, trans ${ }^{3}$, etc.) que llevan años trabajando políticamente en torno a la disidencia de género y corporal. Crip o tullido (que equivale a la traducción de la palabra crip al castellano) hacen referencia a la participación de personas con diversidad funcional en este proceso. Ambos términos han venido utilizándose como una suerte de re-apropiación y desactivación de la injuria, en línea con la propuesta de la teoría queer. Esta alianza tullido-transfeminista ha sido enormemente fructífera y ha supuesto un acicate, e incluso una renovación, para ambos movimientos.

En este artículo pretendo, en primer lugar, trazar una genealogía que permita situar los eventos clave de la alianza queer-crip española así como explicar contextualmente su surgimiento y evolución. En segundo lugar, analizar las dificultades y desafíos que entraña un proyecto político de esta envergadura. Por último, apuntar unas líneas de reflexiones, temores y deseos en torno al futuro de esta alianza. Mi relación con el proceso que me dispongo a analizar tiene dos vertientes. Por un lado, mi implicación activista como feminista y miembro del Foro de Vida Independiente y Divertad (FVID) ${ }^{4}$. 
Por otro, mi rol como investigadora: actualmente estoy realizando el Doctorado en Sociología en la Universidad de Barcelona y mi tesis versa sobre estos temas. Ambas posiciones se complementan y contrarían, yo fluctúo y me desencuentro con cada una de ellas a cada rato. Este texto, indefectiblemente, navega por las mismas contradicciones y, por tanto, se alimenta de las mismas riquezas y posibilidades. valorización positiva y erotización de su diferencia. Lxs queer un colectivo que, al igual que ellxs, no encajan en la norma corporal $\mathrm{y}$, por tanto, plantean desafíos al modelo heteropatriarcal de deseo y sexualidad. Tal y como explica Elena Urko, de Post-Op "no es lo que el postporno puede hacer por las personas con diversidad funcional sino lo que estas personas pueden hacer por el imaginario colectivo"7.

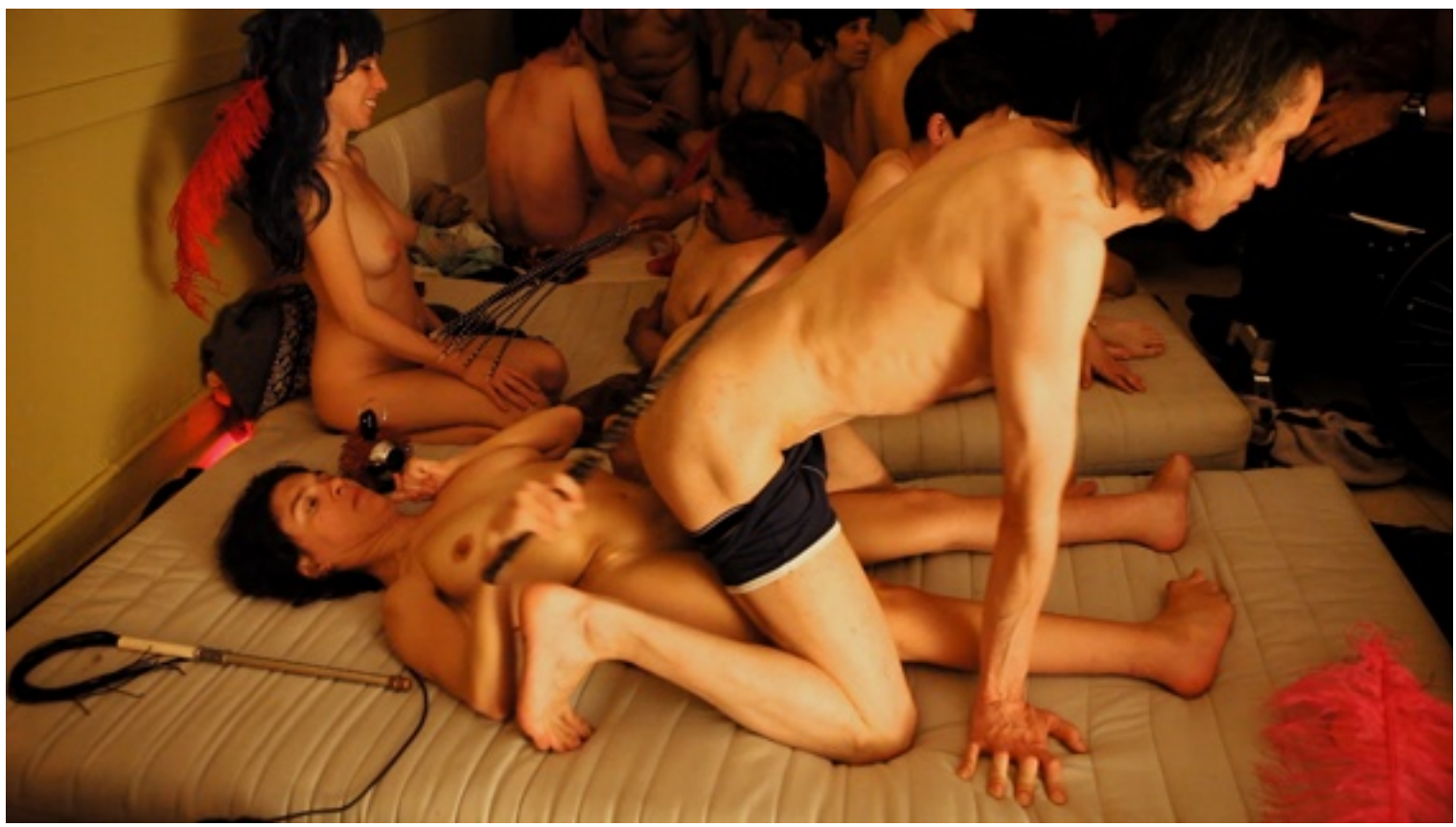

Figura 1 - Taller de postporno y diversidad funcional de Yes, we fuck!

Fuente: Proyecto Yes, we fuck!

\section{Genealogía de la Alianza Queer-Crip}

\section{Un día de placeres y temores}

La primera de las seis historias del documental Yes, we fuck! es un taller de postporno ${ }^{5} \mathrm{y}$ diversidad funcional organizado por Post-Op, un colectivo transfeminista de Barcelona. Este encuentro, este día de risas y caricias, temores y placeres, ortopedias y fluidos, marca un punto de inflexión en el proyecto Yes, we fuck!, y en las vidas y activismos de muchxs ${ }^{6}$ de lxs que participamos. Lxs diversxs funcionales implicados, encuentran un espacio de
Tras el taller, Post-Op se da cuenta de que su postporno pensado para/desde la diversidad corporal, no había tenido en cuenta según qué formas de funcionar, sentir, comunicarse, moverse. Enfrentan el reto de que la inclusión de la diversidad funcional en su trabajo político y artístico (si es que ambas cosas pueden diferenciarse), no se contente y contenga en añadir 'tullido' a la lista de los insultos (re)apropiados por lxs injuriadxs. Comienzan Pornotopedia, un proyecto de diseño colaborativo de juguetes sexuales pensados, esta vez sí, de forma encarnada y situada. 


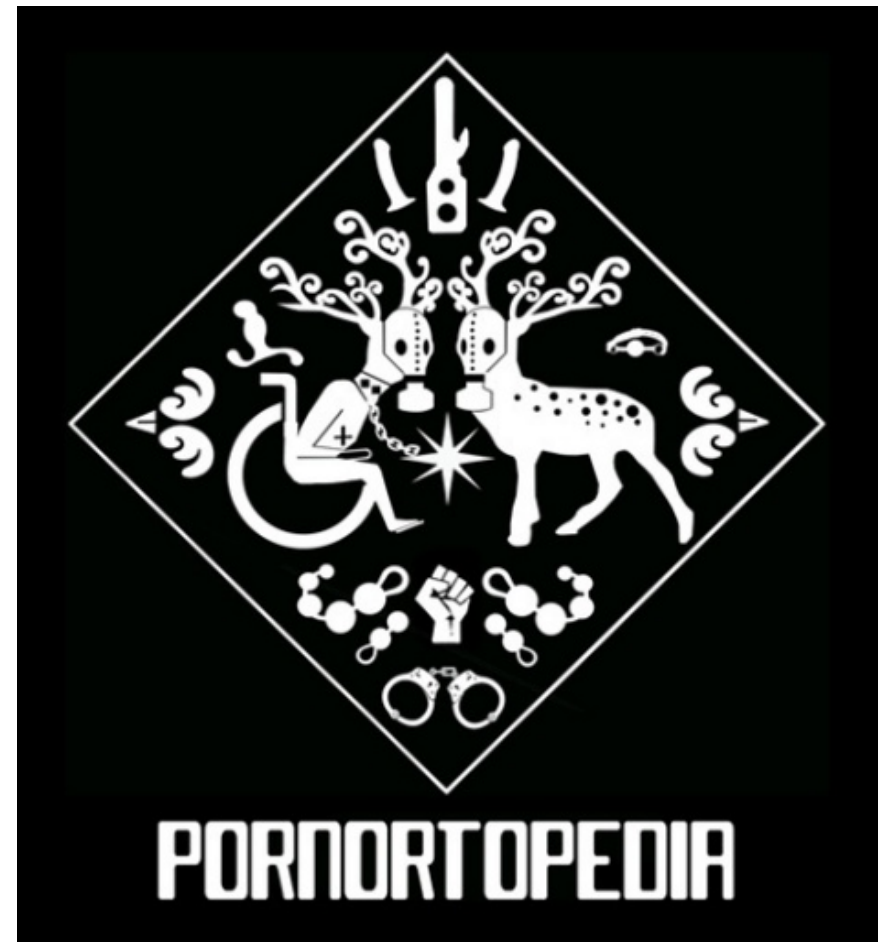

Figura 2 - Pornotopedia el proyecto de juguetes sexuales inclusivos del colectivo Post-Op. Fuente: Colectivo Post-Op

\section{En pro de la 'revolución somatopolítica'}

Azuzadxs por un olvido imperdonable y estimuladxs por el reto de su inclusión, el movimiento queer español ${ }^{8}$ comienza a incluir la diversidad funcional en sus debates y reflexiones teóricas: se generan talleres, encuentros, jornadas y debates que ponen lo crip en el centro del debate: 'Laboratorio: corporalidades, afinidades y alianzas' (en el Octubre Trans 2013), 'Taller de desorden corporal' y 'Actos del Habla' (en el Museo Oral de la Revolución en el Macba, Dic2013), 'Un diálogo en torno al feminismo y la diversidad funcional: reflexiones sobre una intersección necesaria' (en las Jornadas transfeministas: Se va a armar la gorda, Marzo-2014), 'Erótica disidente: reflexiones, re-apropiaciones y resistencias' (en $\mathrm{Ca}$ la dona, Sep-2014), 'Taller de experimentación corporal' y charla 'Se folla como se vive y se vive como se folla' (en el Laboratorio 2014, Nov), 'Cuerpos abyectos, entrelazando vidas', (en la Somateca. Jornadas Queer-crip, Nov2014), 'Relatos marranos' (presentación del libro en La Caníbal, Febr-2015). Este tipo de actividades, suponen una legitimación y un fortalecimiento del discurso de lucha interseccional que plantea el movimiento transfeminista y un paso más en pro de la 'revolución somatopolítica' que diría Paul B. Preciado.

Quizá el evento paradigmático de este interés queer por lo crip, sea la Muestra Marrana 2014 (el festival postporno de Barcelona) en que se presenta como sección especial el 'postporno tullido'. Ante la escasez de videos postporno de estas características, y una vez descartado el porno mainstream que recluye a las personas con diversidad funcional en la sección 'bizarra', lxs activistas transfeministas hacen una llamada a la gente (potencialmente) crip para grabar un video en el que se auto-representen como sujetos deseables y deseantes. Así, nace Nexos, el primer video postporno queer-crip generado en el contexto español. 


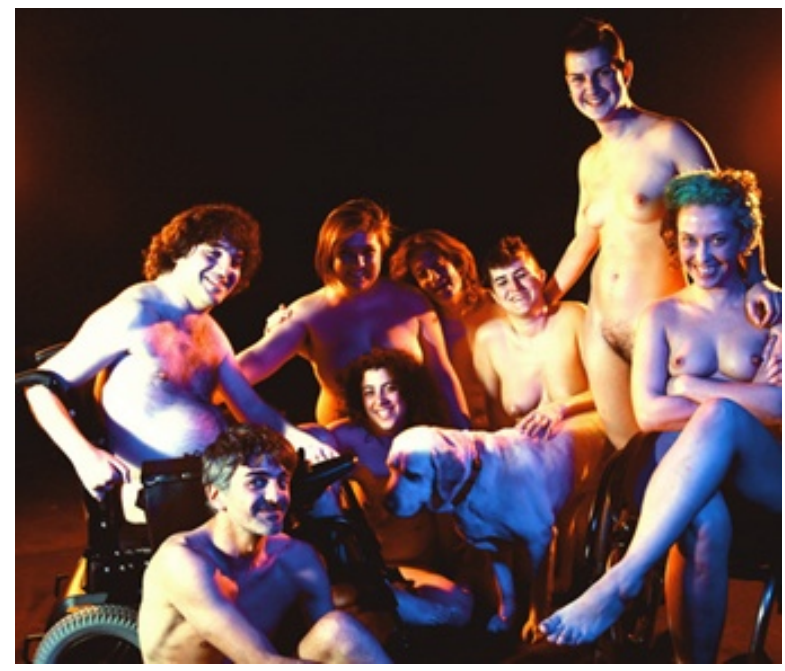

Figura 3 - Lxs protagonistas de Nexos.

Fuente: Colectivo Post-Op

Su presentación en la Muestra Marrana 2014 genera una ovación unánime, un entusiasmo que se transcribe en la petición de presentar el video en otros lugares. Nexos, y sus protagonistas, viajan por todo el país y parte del extranjero. El corto siempre es presentado acompañado del proyecto Pornotopedia y de Yes, we fuck!, de esta forma, lo que realmente se muestra al mundo son las alianzas queer-crip que acontecen en Barcelona9.

El año siguiente, activistas queer $\mathrm{y}$ diversxs funcionales de Madrid, crean el segundo video postporno de estas características (Habitación) que es presentado en la Muestra Marrana 2015 recibiendo el premio al mejor cortometraje. Su proyección, se realiza conjuntamente con
Yes, we fuck! y Nexos. Sus protagonistas deciden encararla realizando una entrada estelar: aparecen desnudos, cubiertos por post-it en que pueden leerse los insultos que tradicionalmente les han estigmatizado (gorda, marica, bollera, travelo, tullido, minusválido, etc), lxs diversxs van en silla de ruedas y lxs dos activistas trans gateando a su lado. Todxs ellxs muestran con orgullo aquellas características corporales (gordura, cicatrices, cuerpos ambiguos en términos de género) y artificiales (pañales, colector $\mathrm{y}$ bolsa para la orina) que normalmente son disimuladas $\mathrm{u}$ ocultadas en pro de la normativización corporal. A continuación, piden al público que se acerque y sustituya los insultos que cubren sus cuerpos por las palabras que prefieran.

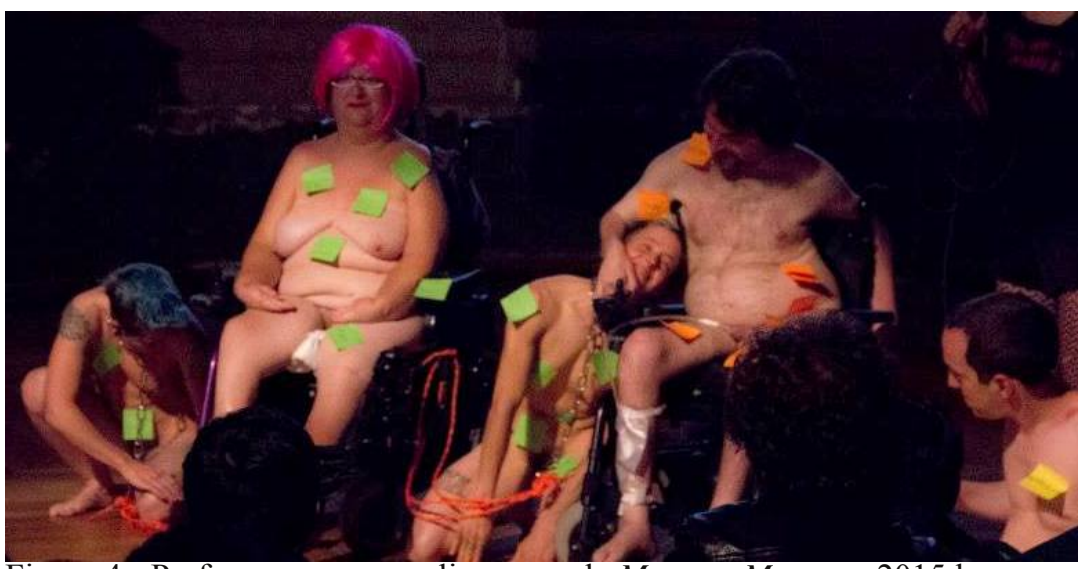

Figura 4 - Performance que realizaron en la Muestra Marrana 2015 lxs protagonistas de Nexos y Habitación.

Fuente: Proyecto Yes, we fuck! 


\section{De la Alianza a la Confianza}

Paralelamente a la creación y difusión de estos proyectos, a nivel local, en Barcelona, vamos impulsando los Pic-nic mutantes, espacios de encuentro en que buscamos pasar de 'la alianza a la confianza', es decir, de la sintonía teórica y discursiva a la afinidad personal. Resulta complejo organizar eventos con un objetivo tan ambicioso, máxime en un contexto de precarización de los espacios de la vida que hace que sobren ganas pero falte tiempo, energía y espacios adecuados. Aun así, cada uno de estos pic-nics, que han tomado diferentes formas (talleres, cinefórums, fiestas), ha ido tejiendo hilos de afecto y redes de cooperación. Por ejemplo, en el libro Relatos Marranos ${ }^{10}$, hubiera sido impensable no incluir, al menos, un texto sobre diversidad funcional.
En sintonía con estos espacios, se genera el proyecto de auto-gestión de la asistencia sexual Assex. Uno de sus impulsores, Antonio Centeno, lo describe de la siguiente forma:

Sin presupuesto, sin local, sin jerarquías, sin vergüenza. Unas diez personas, provenientes del activismo queer, del trabajo sexual, de la asistencia personal y de la diversidad funcional (CENTENO, 2004, p. 113).

El proyecto queda paralizado a los pocos meses por la falta de recursos, espacio, tiempo, concreción, resultados tangibles, etc. Pero el interés por la asistente sexual ${ }^{11}$, continúa siendo un punto de unión de ambos colectivos. Las personas con diversidad funcional se juegan sus derechos sexuales y

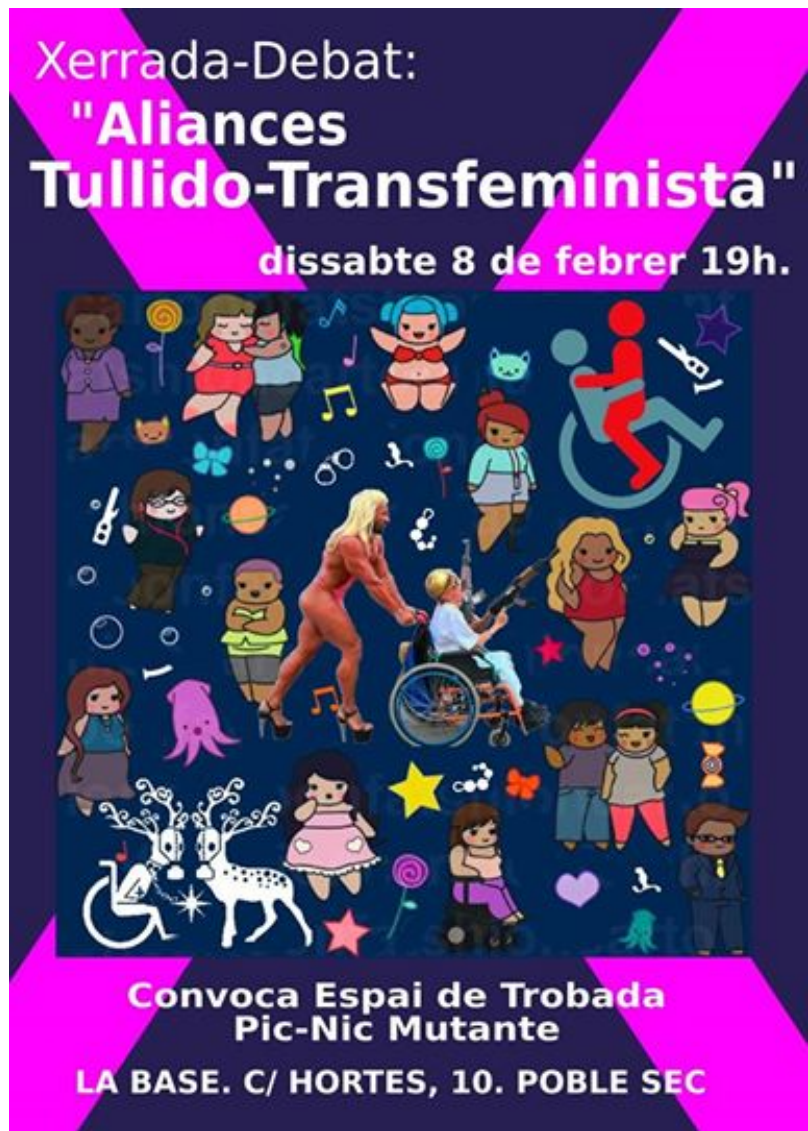

Figura 5 - Cartel de uno de los pic-nic mutantes en el que se convocaba a una "charla-debate sobre alianzas tullido-transfeministas".

Fuente:Pic-nic mutantes 
el acceso a sus cuerpos. Las personas queer encuentran en este recurso una posibilidad de empleo. Y, al mismo tiempo, una vía para legitimar el trabajo sexual y reivindicar su regularización, una de las demandas históricas del feminismo pro sex con el que este grupo se identifica. Por último, tanto lxs transfeministas como lxs diversxs funcionales saben que en el debate sobre asistencia sexual no solo se está discutiendo la regulación de un servicio sino sobre la concepción simbólica de las sexualidades subalternas.

En otros puntos del Estado español, con especial relevancia de ciudades grandes como Madrid, también se desarrollan estas fructíferas sinergias. La Marcha por la Visibilidad de la Diversidad Funcional, evento anual que organiza el Foro de Vida Independiente y Divertad (FVID) con el objetivo de reivindicar los derechos de las personas con diversidad funcional $y$ visibilizar sus demandas, ha contado en los últimos años con la presencia de activistas transfeministas.

\section{A propósito del documental}

¿Y qué ha pasado con Yes, we fuck! en este tiempo? Que el 'we' y el 'fuck' han interpelado a muchas más personas y de una forma mucho más profunda de la que habíamos imaginado. Nos dimos cuenta de que no podíamos hablar de cuerpos no normativos, de deseos negados, de medicalización, de encierro, de exotización, y pretender trazar una línea entre las personas que habían sufrido todas esas violencias por ser categorizadas como 'discapacitadas' y las que las habían sufrido por gordxs, trans, locxs, bolleras, maricas, etc. Porque la sociedad es capacitista $^{12}$ en tanto que heteropatriarcal y racista, porque como dice McRuer (2004) la 'heterosexualidad obligatoria' se retroalimenta y reifica en alianza con la 'capacidad obligatoria'.

Por tanto, el fuck ya no podía limitarse a retratar la práctica sexual habitual de personas con diversidad funcional, porque el documental, al mismo tiempo que se grababa, generaba historias y vivencias que

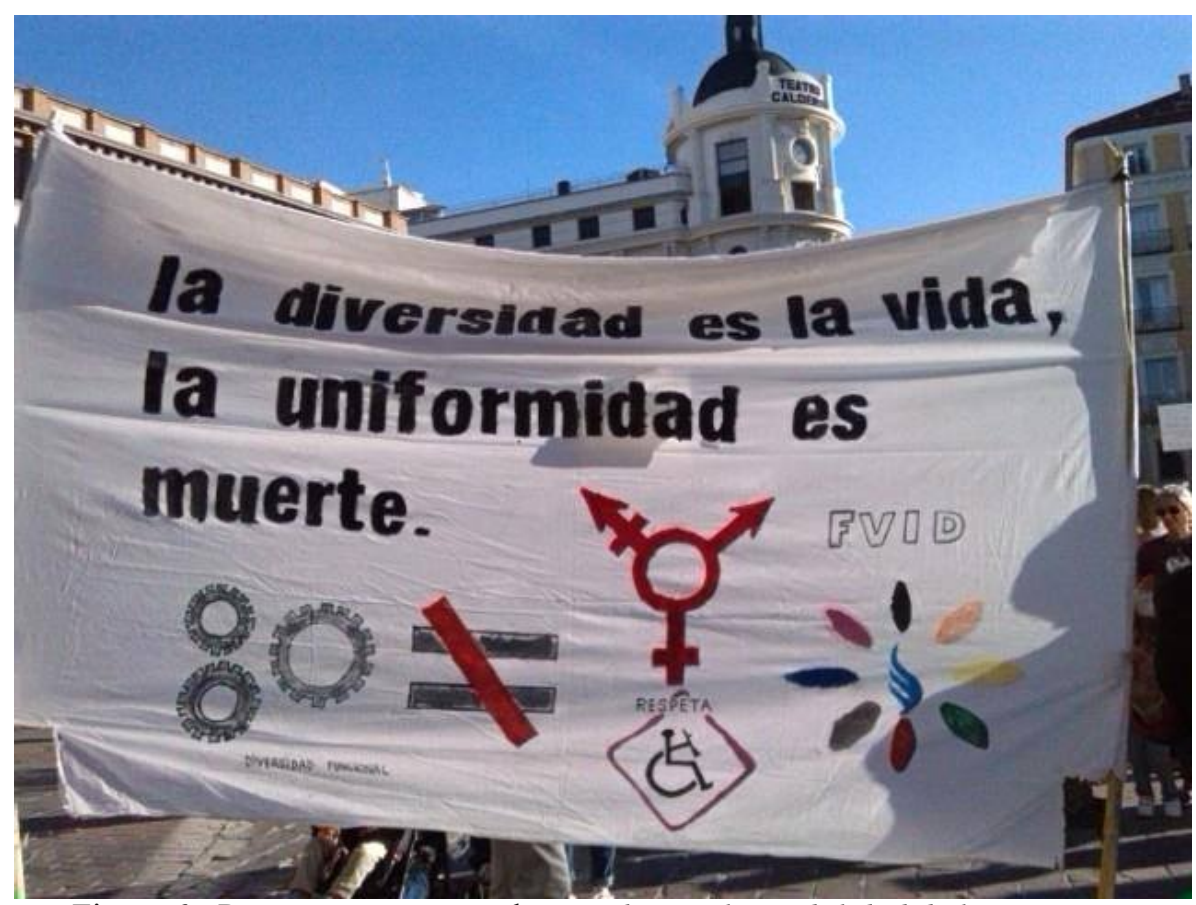

Figura 6 - Pancarta presente en la Marcha por la Visibilidad de la

Diversidad Funcional 2015.

Fuente: Foro de Vida Independiente y Divertad 
merecían ser contadas. Por ejemplo, Mertxe, una mujer ciega que participó en el taller postporno inicial, quiso seguir explorando su sexualidad en ese tipo de espacios. Y una de las historias de Yes, we fuck! narra su experiencia en un taller de 'eyaculación de coños' organizado por un colectivo transfeminista de Madrid.

Y el debate sobre asistencia sexual, llevó a Sole, activista del FVID, a querer demandarla y experimentarla. Y para ello, contó con el apoyo de Teo, un activista trans al que había conocido en un encuentro queer-crip, que tenía interés en explorar ese rol laboral. La experiencia resultó tan exitosa que a día de hoy Sole es una de las activistas más importantes en el contexto español en pro de la asistencia sexual. Y Teo igualmente se ha posicionado en el debate público ${ }^{13}$ y ha continuado ofertando sus servicios como asistente sexual.

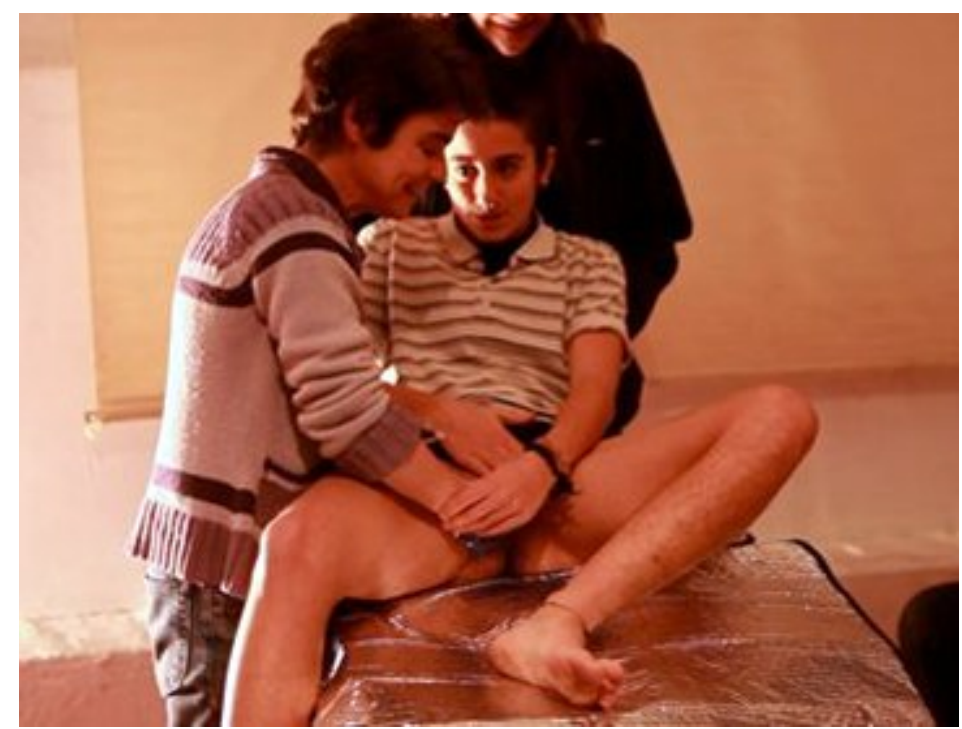

Figura 7 - Kani explicando a Mertxe cómo palpar las glándulas de Skene que producen la eyaculación femenina.

Fuente: Proyecto Yes, we fuck!

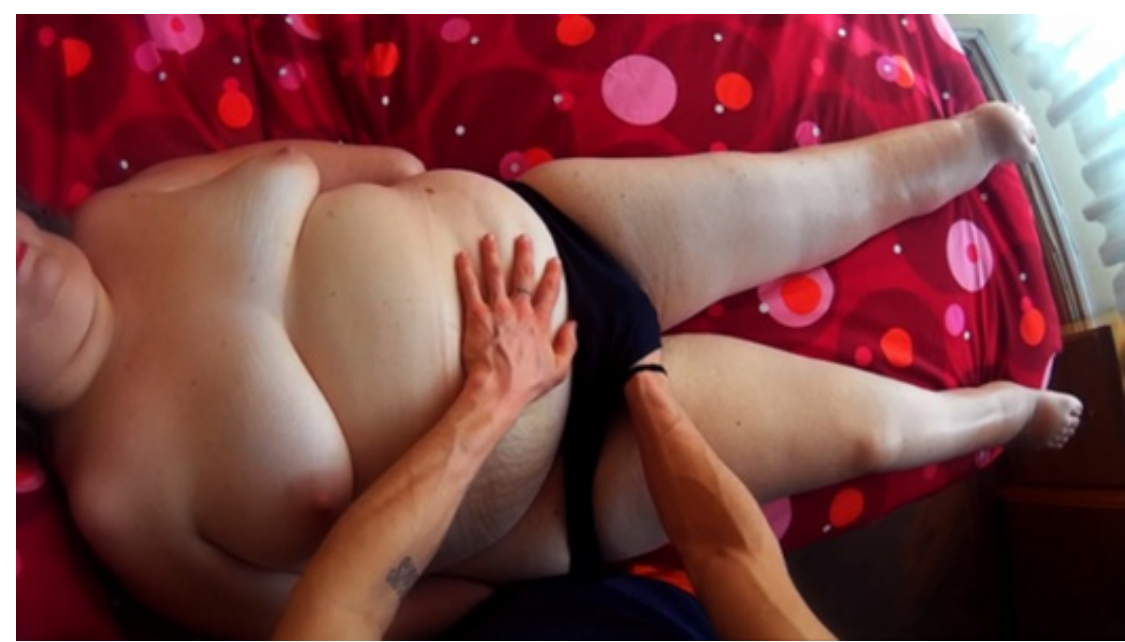

Figura 8 - Las manos de Teo recorriendo el cuerpo desnudo de Sole. Fuente: Proyecto Yes, we fuck! 


\section{Dificultades y Desafíos de la Alianza Queer-Crip}

\section{La Accesibilidad (no solo) Depende de una Rampa}

"Mi cuerpo no es el problema, el problema es una sociedad normalizadora", esta frase podría ser enunciada con igual convicción por unx activista trans, gordx o diversx funcional. Se trata de personas que históricamente han sido, y aun a día de hoy continúan siendo, excluidas, estigmatizadas y segregadas (SANDAHL, 2003; MCRUER, 2006; GUZMAN y PLATERO, 2012). Los distintos poderes las han construido como el otro, aquel diferente, exótico, monstruoso... fruto del pecado, carne de diagnóstico. Ya convivían hace siglos en los Freaks Show, en los que enanos y hermafroditas, deformes y mujeres barbudas, compartían jaula y jornal. En esos tiempos, era más evidente que todxs ellxs escapaban de los cánones de normalidad corporal, belleza y funcionalidad. Y que sus tiempos, sus vidas, cuestionaban las dinámicas de producción y reproducción: no eran asimilables a la lógica capitalista y heteropatriarcal de la familia burguesa que se consolidaba en esos años como la única organización socio-afectiva legítima.

Sin embargo, esta opresión compartida, no ha conducido a fraguar una alianza estable. Según Preciado (2013, s/p):

La purificación identitaria ha impedido que como colectivo somatopolítico subalterno echemos abajo el aparato de la clínica (...) Hemos sido segmentados por unos procesos de emancipación política que han sido fundamentalmente identitarios porque la taxonomía de la clínica del s.XIX nos había dejado en una situación en que la revolución somatopolítica hubiera sido espectacular, es decir, hubiéramos podido hacer una alianza somatopolítica de sifilíticos, tuberculosos, prostitutas... Esta es la revolución a la que yo os llamo

Esta revolución a la que alude Preciado es la que han intentado encarnar lxs activistas concernidos por la alianza queer-crip española. Su lucha se ha desarrollado principalmente en/para los márgenes, en los espacios de la periferia social y sexual. No obstante, paralelamente a este proceso, Yes, we fuck! se ha constituido como una comunidad virtual de encuentro e intercambio de información de personas afines a la reivindicación de la sexualidad de las personas con diversidad funcional. Esta

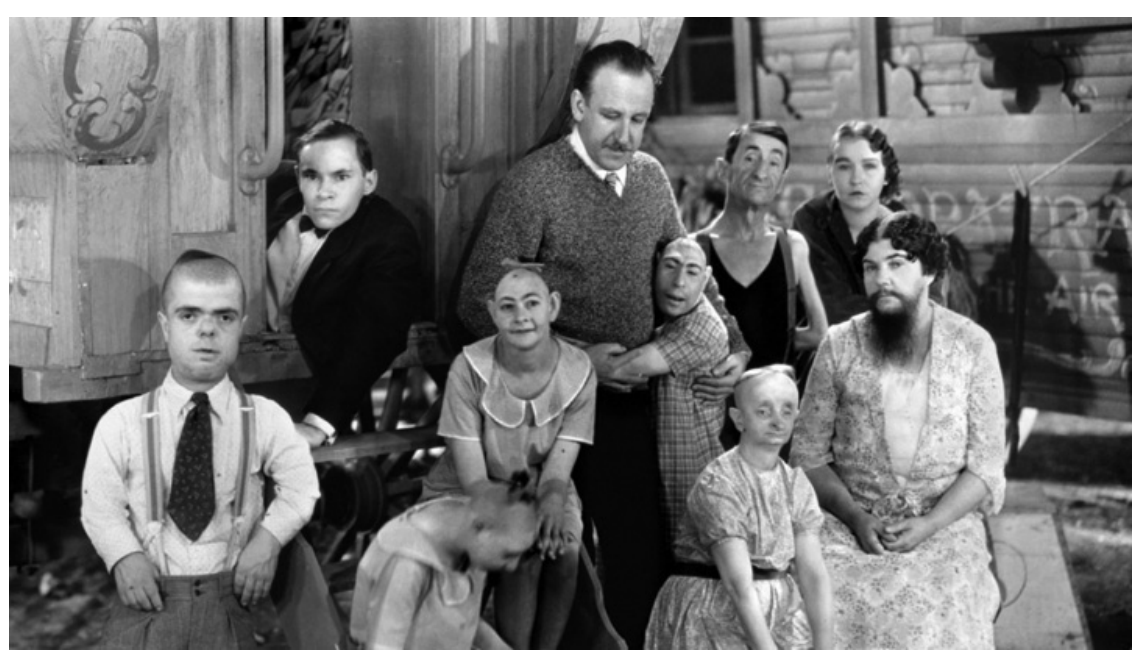

Figura 9 - Imagen de la película Freaks (Tod Browning, 1932) que retrata la vida en un Freak Show. Para rodarla, se utilizaron personas que realmente trabajaban en esos 'espectáculos'.

Fuente: Internet 
identificación colectiva, ha hecho posible que el proyecto pudiera auto-financiarse a través de un Verkami. Al mismo tiempo, la repercusión en medios de comunicación ha excedido cualquier pronóstico. De los blogs y webs alternativas en que comenzó a hablarse del proyecto, Yes, we fuck! ha acabado apareciendo en medios de reconocido prestigio $^{14}$. El colofón de este proceso de difusión fue la presentación del documental en las ciudades de Madrid y Barcelona. La primera, en abril de 2015, se produjo en Centro de Estudios del Museo Reina Sofía, en el marco del Programa de Estudios de la Somateca, con un aforo de 400 personas y una repercusión mediática que alcanzó el telediario de mayor audiencia ${ }^{15}$. La segunda presentación, en Barcelona, fue enmarcada en la inauguración del Creative Commons Film Festival, en el CCCB (Centre de
Cultura Contemporánea de Barcelona), de nuevo con un aforo de 400 personas y una importante repercusión mediática.

No obstante, si bien Yes, we fuck! ha generado y genera en la actualidad un gran interés social y mediático, las alianzas queercrip, que parecieran la encarnación lógica del documental, no han gozado de la misma suerte. Han quedado circunscritas a espacios queer, tanto activistas como artísticos y académicos. De hecho, en las actividades denominadas 'tullido-transfeministas' la presencia de personas con diversidad funcional tiende a ser escasa y, en ocasiones, incluso inexistente.

Lxs activistas queer-crip concernidxs han problematizado esta (no) presencia. En primer lugar, está la cuestión de la accesibilidad física, la cual resulta fácil de

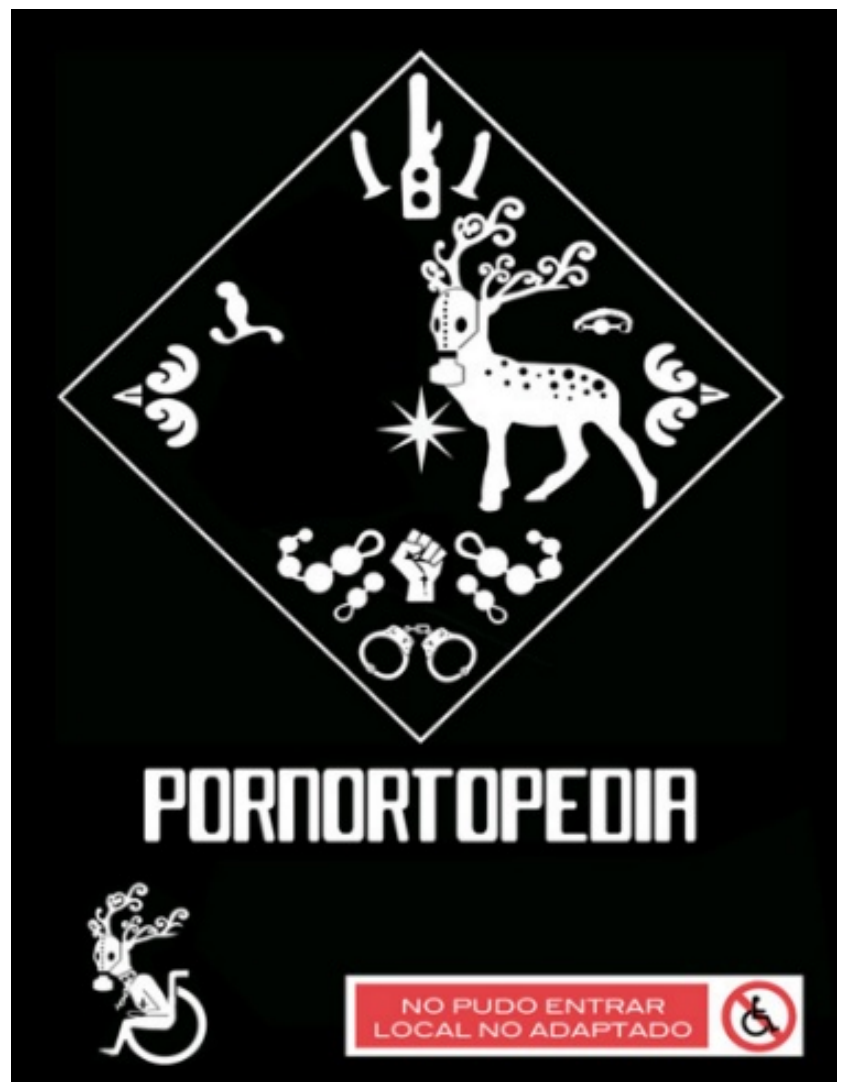

Figura 10 - Imagen de Pornotopedia en la que puede verse a uno de lxs protagonistas (el que va en silla de ruedas) expulsado del espacio central. A su lado puede leerse 'no pudo entrar, local no adaptado'.

Fuente: Colectivo Post-Op 
identificar y no tan sencilla de solventar, sobre todo en un contexto de precariedad económica y escasez de espacios alternativos de socialización. Esta dificultad, ha llevado a tener que suspender actividades que se definían como tullido-transfeministas y luego resultaban inaccesibles para personas en silla de ruedas. Por ejemplo, Helen Torres, respecto a la presentación de Relatos Marranos en el Centro Social Okupado Canmasdeu explica:

Devino una no-presentación. Nada más llegar, nos estrellamos ante la violencia de la opresión que los cuerpos normativos ejercemos sobre los cuerpos con diversidad funcional, con quienes raramente compartimos techo, mesa, y ya no digamos cama. Quizás una cerveza o un café, de vez en cuando. Por eso, cuando un cuerpo normativo dice "accesibilidad" significa "ya veremos cómo lo hacemos", y, cuando una persona que vive la diversidad funcional dice "accesibilidad", quiere decir "voy a ir allí y voy a poder entrar y quedarme ${ }^{16}$.

Varias experiencias de esta índole, han llevado al movimiento transfeminista a ser consciente de su privilegio capacitista, de esta forma, ha habido un esfuerzo significativo por hacer los espacios inclusivos a todas las corporalidades. Por ejemplo, los Octubres Trans ${ }^{17}$ (2014) de Madrid y Barcelona se realizaron en espacios físicamente accesibles y fueron interpretados en lengua de signos. Otros eventos como la presentación de Transfeminismos ${ }^{18}$ o la Muestra Marrana 'se hicieron accesibles' para la ocasión mediante la adaptación del espacio físico. No obstante, parece que las rampas no bastan para que las personas con diversidad funcional se animen a participar.

\section{Opresiones que (des)politizan}

Para entender las dificultades y desafíos que enfrenta la alianza queer-crip, en primer lugar, es fundamental situar histórica $\mathrm{y}$ políticamente a ambos grupos. El movimiento queer español hunde sus raíces en el activismo feminista y el activismo LGBT, que en España tiene un alto nivel de aceptación e influencia en las políticas públicas, con logros históricos como la aprobación del matrimonio homosexual ${ }^{19}$. En las Jornadas Feministas de Granada $(2010)^{20}$ se redactó el 'Manifiesto por la insurrección transfeminista' que puede considerarse el acta fundacional del movimiento queer español. A partir de ahí, comenzaron a consolidarse en el Estado las redes de cooperación y alianza entre sus miembros. Este legado es recogido por el libro Transfeminismos, epistemes y flujos (SOLÁ y URKO, 2013), que ya va por su segunda edición y ha sido presentado en las principales ciudades de la geografía española.

Por su parte, el movimiento en pro de los derechos de las personas con diversidad funcional, se encuentra en una fase de reivindicación de derechos básicos como la educación inclusiva o la accesibilidad universal. El discurso de las organizaciones tradicionales, que cooptan prácticamente todo el movimiento, se mueve entre el modelo médico-rehabilitador ${ }^{21}$ y un modelo social $^{22}$ circunscrito a barreras físicas y de acceso a la información. El Movimiento de Vida Independiente (Independent Living Movement), cuyos postulados suponen una ruptura teórica y práctica en este sentido, ha sido articulado en España a través del Foro de Vida Independiente y Divertad (FVID), organización minoritaria, con logros significativos pero cuantitativamente poco relevantes. Sus demandas, se centran en la reivindicación de la vida independiente a través de la figura de la asistencia personal y, 
hasta ahora, no han puesto el foco en la cuestión de la sexualidad.

El diferente grado de organización política de ambos movimientos no es solo una cuestión numérica, sino que entraña diferencias fundamentales en torno a la autoenunciación y el orgullo. Uno de los rasgos constitutivos del movimiento queer es la reivindicación de su diferencia, desde sus orígenes ha luchado contra la asimilación parte del activismo que lo reivindica, mientras otra lo considera cooptado y apuesta por traducciones e interpretaciones locales y situadas como 'transfeminista' y 'transmarikabollo'.

Por el contrario, el término crip proviene igualmente de la literatura anglosajona pero, en este caso, se trata de obras que no han sido traducidas y que ni si quiera forman parte del

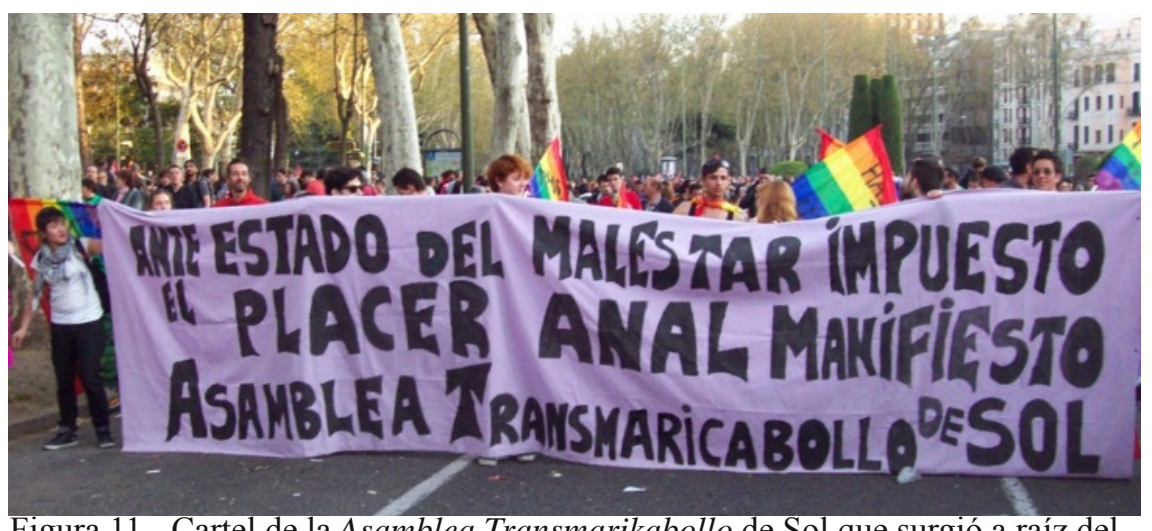

Figura 11 - Cartel de la Asamblea Transmarikabollo de Sol que surgió a raíz del Movimiento 15-M en Madrid.

Fuente: Asamblea Transmaricabollo de Sol

('Fuck normality') y en pro de su diversidad. Respecto a la diversidad funcional, a nivel internacional, sobre todo en el ámbito anglosajón, la disability culture ha construido un corpus teórico y activista sólido, que se enuncia orgulloso de su diferencia y proclama la riqueza de diversidad humana. No obstante, en el contexto español esta reivindicación crip es absolutamente incipiente $^{23}$. Y se encuentra avasallada por un movimiento asociativo de carácter asimilacionista. En las Marchas por la Visibilidad de la Diversidad Funcional, pueden verse eslóganes que reniegan de la 'teoría de la tragedia personal' ${ }^{24}$ pero no por ello se encuentran pancartas que reivindiquen el 'orgullo de ser diversxs' ${ }^{25}$.

La (auto)denominación de estos colectivos refleja a la perfección la distancia que planteo: el término queer ha sido pensado, traducido y puesto en cuestión, hasta tal punto que el debate continua vivo y hay una debate académico local. El concepto 'diversidad funcional', propuesto y defendido por el FVID, es utilizado de manera minoritaria. En consecuencia, la utilización de la palabra tullido es producto más de la construcción de una analogía intencional con lo transfeminista, que del resultado de un proceso de auto-enunciación por parte de las personas con diversidad funcional.

El diferente grado de politización de ambos colectivo es especialmente acusado, paradójicamente, en el área de unión que han encontrado: la reflexión teórica y práctica sobre la sexualidad, el cuerpo y el género. Para el movimiento queer, esta reflexión constituye el eje central de su lucha política. Por el contrario, el movimiento de personas con diversidad funcional se encontraba despolitizado en ese sentido. Tal y como explica Antonio Centeno al respecto del taller postporno "Era un encuentro entre las perras más perras de Barcelona y dos o tres tíos que 
habíamos follado poco y mal, la mayoría de las veces pagando" 26 . A este respecto, resulta fundamental recordar que las personas con diversidad funcional han sido históricamente consideradas seres asexuales: no deseantes, mucho menos deseables. Sus derechos sexuales y reproductivos son sistemáticamente transgredidos, a pesar de los avances legislativos en este sentido. No reciben educación sexual, no se socializan en los lugares habituales (falta de inclusión construido discursivamente la alianza queercrip, ha remitido mayoritariamente al imaginario transfeminista. Resulta igualmente lógico, por tanto, que muchas personas con diversidad funcional no se hayan sentido interpeladas por esta llamada a la 'revolución somatopolítica'.

\section{Desear y otras ficciones}

Yes, we fuck! ha impulsado la construcción

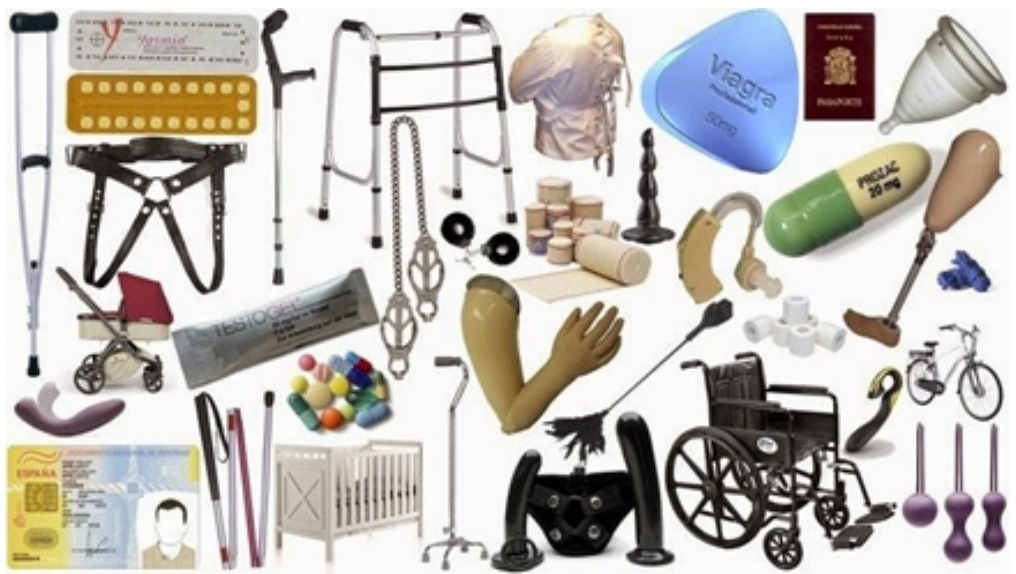

Figura 12 - Imagen de las Jornadas Queer-Crip de la Somateca (Nov-2014) en la que pueden verse elementos relacionados con la diversidad funcional (prótesis, órtesis, medicinas, elementos para la higiene personal) y con lo queer (dildos y otros juegues sexuales como los propios del BDSM, elementos de identificación binarista, etc).

Fuente: Museo Reina Sofía

educativa y laboral, inaccesibilidad de los lugares de ocio, escasez de recursos económicos, etc) y viven mayoritariamente segregados (bien en residencias, bien en el domicilio familiar sin suficientes apoyos para llevar a cabo una vida independiente). A esta exclusión de los elementos que facilitan el desarrollo de una vida afectivo-sexual normalizada, hay que sumarle la opresión patriarcal y capacitista que marca sus cuerpos como 'indeseables'.

En este contexto, resulta lógico que haya sido el mundo queer el que haya recibido con más facilidad y entusiasmo la idea de una unión tullido-transfeminista. De hecho, el tipo de lenguaje, las referencias teóricas y los guiños humorísticos mediante los que se ha de una alianza entre activismos que ha supuesto un enriquecimiento para los sujetos y proyectos implicados. Lxs activistas transfeminista han renovado y ampliado su imaginario, han encontrado nuevos desafíos para su trabajo artístico, su proyecto político y su práctica sexual (si es que estas cosas pueden diferenciarse). Esta alianza ha supuesto un fortalecimiento de su discurso de lucha interseccional y, al mismo, tiempo les ha conllevado un replanteamiento de postulados y (auto) cuestionamiento de privilegios.

Por su parte, lxs diversxs funcionales han encontrados espacios y personas que perciben sus cuerpos como deseables, que sexualizan sus prótesis y órtesis, que ven en lo que han 
vivenciado como defectos y vergüenzas, elementos sexys y novedosos. La incontinencia urinaria, elemento habitualmente traumático para las personas con diversidad funcional, es convertida en Nexos en una lluvia dorada. Este proceso de empoderamiento corporal y político está construyendo un incipiente orgullo tullido, que comienza a salir del armario de la conmiseración y el paternalismo.

Esta alianza ha generado que, a día de hoy, ambos grupos sean conscientes ( $\mathrm{y}$ tiendan a ser consecuentes) con la existencia del otro y la hermanación de sus luchas. Por ejemplo, en la última manifestación del Octubre Trans (2015) ya hubo presencia de activistas diversxs funcionales. No obstante, resulta evidente que todo proceso político bebe de una memoria colectiva $\mathrm{y}$, por tanto, sus logros no deben ser valorados de forma presentista y personalista. Yes, we fuck! ha sido posible porque antes hubo documentales como Almas con sexo (GONZÁLEZ, 2003), El sexo de los ángeles (TORO, 2004) o Editar una vida (DE LA MORENA, 2005). Hablar de sexo ha sido posible porque antes se había hablado de dignidad, de derechos humanos y de igualdad. Nombrar(se) como tullidxs ha sido posible porque antes se había conceptualizado diversidad funcional $y$ porque otrxs se habían nombrado como maricas, locxs, bolleras, gordxs.

Hablar de alianzas queer-crip entraña, también, el riesgo de pensar cada grupo como ente independiente cuando, tal y como explica Lucas Platero, "siempre ha habido personas en la intersección" 27 , es decir, siempre han existido diversxs funcionales LGBT y viceversa. Estas personas, que habitaban la encrucijada, ya eran conscientes de que su opresión no tenía un nombre unívoco ni era la suma de dos opresiones independientes que podían resolverse autónomamente: un día en la manifestación del orgullo gay, otro en la de los derechos de las personas "discapacitadas". Antes de Yes, we fuck! y la alianza queer-crip, ya había habido intentos en el contexto español de aunar luchas y significados ${ }^{28}$, destaca por ejemplo el trabajo de la comunidad sorda en torno a la cuestión LGBT. Sin embargo, se trata de experiencias aisladas y minoritarias, que no han contado ni con recursos suficientes ni con un contexto proclive para su fortalecimiento y difusión. A este respecto, hay que tener en cuenta que la llegada de Internet y la popularización de las redes sociales marcan un punto de inflexión en el activismo político.

Por tanto, lo que la (auto)denominada alianza tullido-transfeminista ha aportado a esta realidad interseccional es un marco discursivo de politización colectiva, en el que lo virtual ha resultado clave. Ha puesto nombre y proyecto político a experiencias individuales que tendían a ser vivenciadas y conceptualizadas como independientes, debido a que no existía una comunidad que se posicionara en esa encrucijada. A día de hoy la estamos construyendo, y ese 'nosotrxs' se traduce en la generación de proyectos políticos y artísticos, pero también en la proliferación de vínculos personales, afectivos, sexuales... Si algo hemos tenido claro es que la revolución será corporal o no será.

Yes, we fuck! acaba de ser premiado como mejor documental por el festival postporno de Berlín, el más importante del continente europeo. Lo que no se nombra no existe, y lo que no se ve, difícilmente se imagina. Por eso, este documental, así como Nexos, Habitación o Vivir y otras ficciones ${ }^{29}$ son productos culturales destinados tanto a retratar como a generar deseos. Cuantas más imágenes tengamos de lo que podría ser esa sexualidad disidente y orgullosa, más posibilidades tendremos de experimentarla y disfrutarla. Deseemos la ficción y ficcionemos el deseo. 


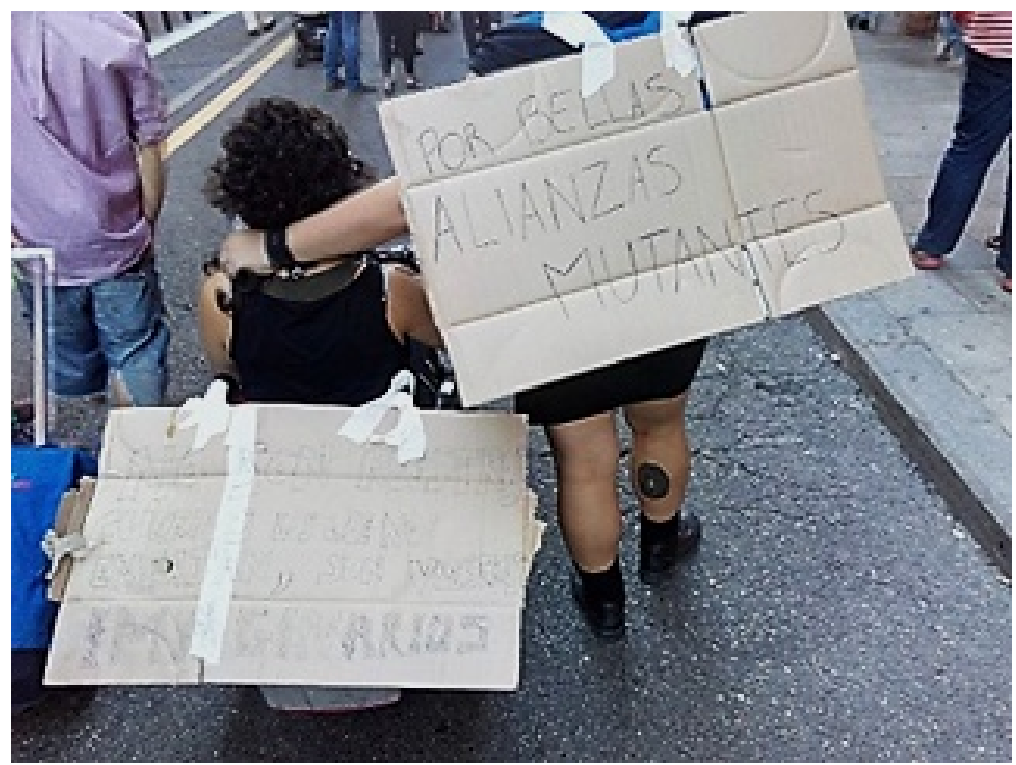

Figura 13 - Imagen de la última Marcha por la Visibilidad de la Diversidad Funcional (Sep-2015) en la que caminan juntas una activista diversa funcional (a la izquierda) y una queer (a la derecha). La primera lleva un cartel que pone 'No son nuestros cuerpos los que no encajan, son vuestros imaginarios'. En el de la segunda pone 'por bellas alianzas mutantes'.

Fuente: Foro de Vida Independiente y Divertad

1 Este concepto, acuñado por el Foro de Vida Independiente en 2001, al contrario que otros términos peyorativos como 'discapacitados' o 'minusválidos', pone el énfasis en que todas las personas tienen su manera de funcionar (de moverse, comunicarse, expresarse) y la desigualdad se debe a la discriminación que sufren aquellas cuyas diferencias funcionales son catalogadas como 'menos valiosas'.

2 El transfeminismo es un término acuñado en el contexto español con el objetivo de nombrar un feminismo que busca abrirse a otros sujetos tradicionalmente relegados por las luchas feministas, como las mujeres trans, las trabajadoras sexuales o las migrantes. El prefijo 'trans' hace un guiño a la cuestión trans y, al mismo tiempo, alude al tránsito (por ejemplo de lxs migrantes) y a la fluidez de las categoría de género y sexualidad.

3 'Trans' se utiliza para designar a aquellas personas que transitan dentro de las dicotomías sexogénero, tanto las transexuales como las transgénero. Utilizar solo el prefijo trans permite que esta categoría resulte inclusiva para ambos colectivos así como para otras personas que vivan su tránsito de sexo/género en otros términos.

4 Comunidad virtual de personas que, principalmente en España, promueven el Movimiento de Vida Independiente, el cual defiende la inclusión real de las personas con diversidad funcional en la sociedad. Para ello, se aboga por la desinstitucionalización y la provisión de apoyos (asistencia personal) para que las personas con diversidad funcional pueden gestionar sus vidas. El lema del movimiento es claro "Nada sobre nosotros/as sin nosotros/as".

5 El postporno es un movimiento que busca, mediante la auto-representación de corporalidades y prácticas disidentes, promover otro imaginario sexual que cuestione lo discriminatorio (sexista, capitalista, racista, edadista, etc) de la pornografía mainstream. Preciado (2008) lo define como "el efecto del devenir sujeto de aquellos cuerpos y subjetividades que hasta ahora sólo habían podido ser objetos abyectos de la representación pornográfica".

6 En este texto se utilizará la " $\mathrm{x}$ " con el objetivo de "desgenerizar" los sustantivos y adjetivos de forma que incluyan a todas las personas, también a aquellas que no se sienten identificadas dentro del binarismo de género.

7 Extracto de la entrevista realizada a Elena Urko con motivo de mi tesis doctoral.

8 En este texto se utilizará 'queer' como sinónimo de 'transfeminista' por entender que ambos conceptos tienen suficientes puntos en común como para poder ser abordados de esa manera, a pesar del sentimiento de incomodidad de algunxs activistas al 
respecto en el que se profundizará más adelante en el texto.

9 Hasta la fecha, estos tres proyectos han sido presentados conjuntamente a nivel nacional (Barcelona, Zaragoza, Sevilla, Pamplona) e internacional (Suiza, Francia y México).

10 Libro de relatos eróticos, coordinado por la activista transfeminista Helen Torres con motivo de la Muestra Marrana 2014, que propone 'un recorrido por deliciosas aberraciones que cuestionan a los cuerpos imperturbables al flujo del tiempo y el deseo. las sirenas que te guíen serán voces desnudas de pudor entonando la antigua canción que dice que quien tiene cuerpo desea, sea este tullido, viejo, gordo, marika, bollero, trans, anoréxico, difuso, incompleto, fuera de lugar...'. En él, se incluye la entrevista 'Gracias a mi cuerpo' realizada al activista diverso funcional Antonio Centeno.

11 Assex defendía un modelo de asistencia sexual limitado al apoyo a la persona con diversidad funcional en el acceso sexual a su propio cuerpo, por ejemplo, desvistiéndola, ayudándola a masturbarse o a tener relaciones sexuales con su pareja. No obstante, otros modelos como el de la organización Tandem Team, defienden una visión diferente de la asistencia sexual que incluye las relaciones sexuales entre la persona asistida y la asistente. Para más información: GARCÍA-SANTESMASES, A; BRANCO, C. 2016 en prensa.

12 'Capacitista' hace referencia al tipo de discriminación que se ejerce contra las personas con diversidad funcional por considerar que 'no son capaces', que 'son menos capaces' o que sus capacidades 'son menos valiosas'. Esta opresión es fruto de la pervivencia de la dicotomía capaz-incapaz que genera que las personas que son posicionadas en la segunda categoría sean sistemáticamente discriminadas. Esta terminología proviene del mundo anglosajón en que se utiliza 'ableist' para designar la discriminación y 'ableism' (que podría traducirse como 'capacitismo') para aludir el sistema discriminador.

13 Tanto Sole como Teo han publicado reflexiones a raíz de su experiencia en el blog de Yes, we fuck! (http://yeswefuck-blog.tumblr.com/), pueden consultarse en la sección de Referencias de este artículo.

14 Destaca su aparición en: prensa escrita (Diagonal, La Directa, El Periódico, El Diario,
Liberation, El País, El Mundo), radio (Catalunya Radio, varios programas de Cadena SER Radio Nacional de España) y televisión (Barcelona Televisió, La Sexta, Televisión Española).

15 El 21/4/2015 una noticia sobre Yes, we fuck! apareció en el telediario de las $15 \mathrm{~h}$ de Televisión Española.

16 Extracto del comunicado de Helen Torres, disponible en: http://www.verkami.com/projects/9546relatos-marranos-antologia/blog/15533-nopresentacion-de-relatos-marranos-en-can-masdeu

$17 \quad$ El mes de octubre ha sido el mes elegido por el movimiento por la Despatologización Trans para visibilizar su lucha, de ahí el nombre 'Octubre trans'.

18 Transfeminismos, epistemes y flujos (SOLÁ y URKO, 2013)

19 España fue el tercer país del mundo en aprobar el matrimonio entre personas del mismo sexo.

20 Jornadas estatales que se celebran cada 10 años y tienen una importancia fundamental para el movimiento feminista español.

21 El modelo médico ve a la persona con diversidad funcional como un cuerpo dañado que debe someterse a tratamiento y rehabilitación para asimilarse lo máximo posible a los estándares de normalidad. Este modelo se centra en la problemática individual, obviando los factores sociales que influyen en esta situación.

22 El modelo social se centra en identificar y denunciar las barreras que dificultan la participación en la sociedad de las personas con diversidad funcional. Desde esta perspectiva, el problema no lo tienen los individuos 'diferentes' sino la sociedad que les discrimina.

$23 \mathrm{Si}$ bien la construcción política de la identidad 'tullida' es algo muy reciente en el contexto español, lxs activistas del FVID llevan más de una década trabajando en torno a la idea de diversidad funcional $\mathrm{y}$ de dignidad intrínseca. Para más información: El modelo de la diversidad (Palacios \& Romañach, 2006).

24 La teoría de la tragedia personal hace referencia a la construcción social que enuncia que la diversidad funcional es una realidad indeseable, que 
necesariamente origina un gran sufrimiento a la persona que la tiene.

25 No obstante, ya hay activistas que reivindican que la Marcha debería ser un espacio de orgullo de la diferencia, respecto a este debate puede consultarse: http://www.derechoshumanosya.org/node/1185

26 Entrevista realizada a Antonio Centeno con motivo de mi investigación doctoral.

27 Entrevista realizada a Lucas Platero con motivo de mi investigación doctoral.

28 Para más información: PLATERO, R.L. Una mirada crítica sobre la sexualidad y la diversidad funcional: Aportacioes artísticas, intelectuales y activistas desde las teorías tullidas (crip) y queer. In SOLÁ, M y URKO, E, Transfeminismos. Epistemes, fricciones y flujos. Tafalla: Txalaparta, 2013, pp. 194211

29 Título de la nueva película de Jo Sol (Jordi Soler) co-protagonizada por Antonio Centeno, activista con diversidad funcional y co-director de Yes, we fuck! Más información en: http://viviryotrasficcionesmovie.com/

\section{Referências}

ARNAU, Soledad. De la compresa a la masturbación. De lo personal a lo sexual. Yes, we fuck-blog. Disponible en $<\mathrm{http}$ ://yeswefuckblog.tumblr.com/post/109664598589/de-lacompresa-a-la-masturbaci $\% \mathrm{C} 3 \% \mathrm{~B} 3$ nde-lopersonal-a>. Fecha de consulta en 12 de novembro de 2015.

CENTENO, Antonio. Simbolismos y alianzas para una revuelta de los cuerpos. Educació Social. Revista d'Intervenció Socioeducativa, n. 58, p. 101-118, 2014.

CENTENO, Antonio. La revolución de los cuerpos. Derechos Humanos ¡YA! Disponible em $<$ http://www.derechoshumanosya.org/node/1 185>. Fecha de consulta en 12 de novembro de 2015 .
DE LA MORENA, Raúl. Editar una vida. España: Raúl de la Morena, 2005.

FERNÁNDEZ, June. La pornografía es una noción política. Entrevista realizada a Beatriz Preciado para el periódico Diagonal, 24/07/08. Disponible en $<$ https://www.diagonalperiodico.net/culturas/ la-pornografia-es-nocion-politica.html>.

Fecha de consulta en 12 de novembro de 2015.

GARCÍA-SANTESMASES, A; BRANCO, C. Fantasmas y fantasías: controversias sobre la asistencia sexual para personas con diversidad funcional. Pedagogia y Trabajo Social. Revista de Ciencias Sociales Aplicadas, v. 6, n. 1, s/p, 2016-en prensa.

GARCÍA-SANTESMASES, Andrea. Dilemas feministas y reflexiones encarnadas: El estudio de la identidad de género en personas con diversidad funcional física. Athenea Digital. Revista de Pensamiento e Investigación Social, v. 4, n. 14, p. 19 - 47, 2014.

GONZÁLEZ, Pilar. Almas con sexo. España y Dinamarca: Pilar González Rams, 2003.

GUZMAN, Paco. Panegírico. Minusval 2000. Disponible en $<$ http://www.minusval2000.com/literatura/arc hivosLiteratura/panegirico.html $>$. Fecha de consulta en 12 de novembro de 2015.

GUZMÁN, Paco; PLATERO, Lucas. Passing, enmascaramiento $\mathrm{y}$ estrategias identitarias: diversidades funcionales $y$ sexualidades no-normativas. En Platero, R. L. (Ed.), Intersecciones: Cuerpos y Sexualidades en la encrucijada (pp. 125158). Barcelona: Bellaterra.

MCRUER, Robert. Crip Theory: Cultural 
Signs of Queerness and Disability. New York: New York University Press, 2006.

PALACIOS, Agustina; ROMAÑACH, Javier. El modelo de la diversidad. Santiago de Compostela: Ediciones Diversitas, 2006.

PLATERO, Raquel (Lucas). Una mirada crítica sobre la sexualidad y la diversidad funcional: Aportaciones artísticas, intelectuales y activistas desde las teorías tullidas (crip) y queer. En: SOLÁ, Mirian; URKO, Elena. Transfeminismos. Epistemes, fricciones y flujos. Tafalla: Txalaparta, 2013, p. 194 - 211.

PRECIADO, Beatriz. ¿La muerte de la clínica? Conferencia en Programa de Prácticas Críticas. Somateca 2013. Vivir y resistir en la condición neoliberal. Disponible en $<$ http://www.museoreinasofia.es/multimedia/ muerte-clinica $>$. Fecha de consulta en 12 de novembro de 2015.

SOLÁ, Miriam; URKO, Elena. Transfeminismos, epistemes y flujos. Tafalla: Txalaparta, 2013.

TORO, Frank. El sexo de los ángeles. España: Kinelogy Producciones Audiovisuales, 2004.

TORRES, Helen; DE PRADA, Aida (Orgs.). Relatos marranos. Antología. Barcelona: Pollen, 2014.

TORRES, Helen. (No) presentación de Relatos marranos en Can Masdeu. Verkamiblog. Disponible en $<$ http://www.verkami.com/projects/9546relatos-marranos-antologia/blog/15533-nopresentacion-de-relatos-marranos-en-canmasdeu>. Fecha de consulta en 12 de novembro de 2015.
VALLS, Teo. Pensamientos de un asistente personal sobre la figura laboral de asistencia sexual. Yeswefuck-blog. Disponible en $<$ http://yeswefuckblog.tumblr.com/post/109499559209/pensam ientos-de-un-asistente-personal-sobre-la> . Fecha de consulta en 12 de novembro de 2015. 